showed trace aortic regurgitation and a mean gradient of 8 $\mathrm{mm} \mathrm{Hg}$. Estimated aortic orifice area is $2.1 \mathrm{~cm}^{2}$ (indexed orifice area: $1.3 \mathrm{~cm}^{2} / \mathrm{m}^{2}$ ). Left ventricular end-diastolic and end-systolic diameters are 46 and $30 \mathrm{~mm}$, respectively (Figure 1). Left ventricular ejection fraction is preserved.

\section{DISCUSSION}

To our knowledge, this case represents the longest followup of a functional aortic homograft after implantation. Remarkably, the patient was in her mid-30s when she underwent surgery, putting her at high risk of early valve degeneration. Several points emerge from this case. Although we and others have sought to determine the precise mechanisms responsible for tissue valve deterioration, ${ }^{1,2}$ more work is required to translate this knowledge into improved patient outcomes. Homograft degeneration is partly due to direct and indirect immune reactions elicited by the persistence of living cells and protein remnants on the homograft cusps and wall. Interestingly, this case illustrates what we call the "homograft paradox," namely, that fresh homografts appear to be more durable and exhibit less degeneration despite a higher likelihood of eliciting an immune reaction. This might be due to their better ability to adapt to their new hemodynamic environment, therefore reducing stresses on the aortic cusps and wall. Similarly, use of a total root replacement technique (versus subcoronary implantation) is thought to favor the long-term durability of homografts, ${ }^{3}$ possibly due to better biomechanics of the homograft root, decreased mechanical stresses on the cusps, and more optimal ventricular workload and coronary blood flow. ${ }^{4}$

Bioprosthetic valve degeneration is characterized by lipid-rich inflammatory cell infiltration, ${ }^{2}$ a process similar to atherosclerosis, and is associated with smoking and concomitant coronary artery disease. ${ }^{5}$ In our patient, no recurrence of coronary artery disease was evidenced, mirroring the durability of the homograft. Her latest lipid profile is normal; she is normotensive, physically active, and eats a balanced diet. This underlines the potential impact of a healthy lifestyle and control of atherosclerotic risk factors in tissue valve recipients.

\section{CONCLUSION}

In conclusion, this case demonstrates the potential longterm functionality of an aortic homograft implanted as a total root in a young patient. With increased understanding of the mechanisms responsible for tissue valve degeneration, it is hoped that the durability of these valve substitutes can be greatly enhanced, including in the younger patient population.

\section{References}

1. Smith JD, Ogino H, Hunt D, Laylor RM, Rose ML, Yacoub MH. Humoral immune response to human aortic valve homografts. Ann Thorac Surg. 1995;60(2 Suppl): S127-30.

2. Shetty R, Pibarot P, Audet A, Janvier R, Dagenais F, Perron J, et al. Lipid-mediated inflammation and degeneration of bioprosthetic heart valves. Eur J Clin Invest. 2009;39:471-80.

3. Lund O, Chandrasekaran V, Grocott-Mason R, Elwidaa H, Mazhar R, Khaghani A, et al. Primary aortic valve replacement with allografts over twenty-five years: valve-related and procedure-related determinants of outcome. J Thorac Cardiovasc Surg. 1999; 117:77-90; discussion 91.

4. Davies JE, Parker KH, Francis DP, Hughes AD, Mayet J. What is the role of the aorta in directing coronary blood flow? Heart. 2008;94:1545-7.

5. El-Hamamsy I, Zaki M, Stevens LM, Clark L, Rubens M, Melina G, et al. Rate of progression and functional significance of aortic valve and root calcification following freestyle versus homograft aortic root replacement: results from a prospective randomized trial. Circulation. In press.

\title{
Pericardial defects and traumatic tricuspid valve rupture: A serendipitous association?
}

Giovanni Battista Luciani, MD, Fabio Patelli, MD, Giuseppe Faggian, MD, and Alessandro Mazzucco, MD, Verona, Italy

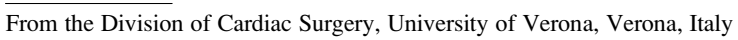
Disclosures: None.

Received for publication May 15, 2009; revisions received June 3, 2009; accepted for publication June 20, 2009; available ahead of print July 30, 2009.

Address for reprints: Giovanni Battista Luciani, MD, Division of Cardiac Surgery, University of Verona, OCM Piazzale Stefani 1, Verona, 37126, Italy (E-mail: giovanni.luciani@univr.it).

J Thorac Cardiovasc Surg 2010;139:e142-4

$0022-5223 / \$ 36.00$

Copyright (c) 2010 by The American Association for Thoracic Surgery doi:10.1016/j.jtcvs.2009.06.018
}

Traumatic tricuspid valve rupture (TTR) after blunt chest trauma is a fairly infrequent condition, although it is the most commonly reported traumatic valve injury. ${ }^{1}$ Rupture of the pericardium after chest trauma is relatively more frequent, but very few cases of TTR associated with pericardial rupture have been identified. ${ }^{2}$ Congenital pericardial defects are also rare with nearly 200 cases reported to date. ${ }^{3}$ Here reported is the case of successful repair of TTR associated with a pericardial defect. The issue whether the pericardial defect is a consequence of trauma or 


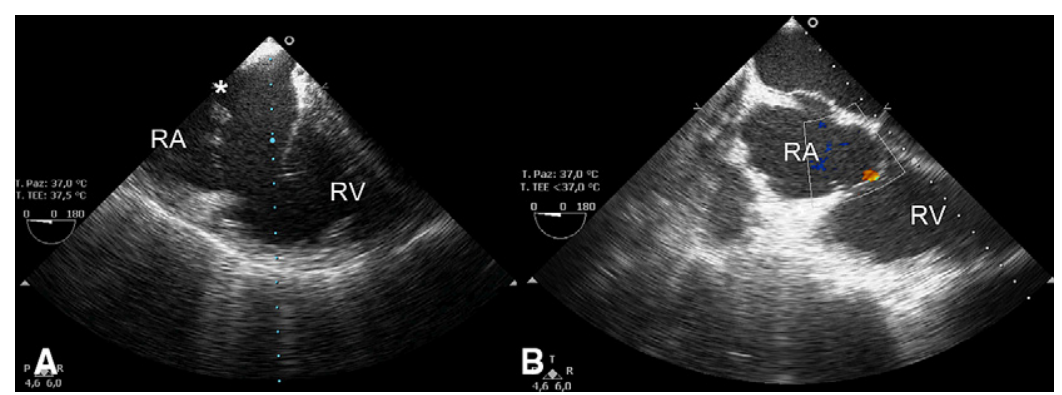

FIGURE 1. A, Prerepair TEE showing flail anterior papillary muscle of tricuspid valve (asterisk). B, Postrepair examination shows no residual TV regurgitation. $R A$, Right atrium; $R V$, right ventricle.

a congenital defect predisposing to valve rupture remains controversial and is herein discussed.

\section{CLINICAL SUMMARY}

A 46-year-old previously healthy man came to the hospital after a motor ski crash with blunt chest trauma. A computed tomographic scan revealed enlargement of the right cardiac chambers and bilateral pleural effusions. Severe tricuspid valve (TV) regurgitation was diagnosed on the basis of 2-dimensional transesophageal echocardiography (TEE) with evidence of ruptured anterior papillary muscle and severe right chamber volume overload (Figure 1, A). The patient had dyspnea and mild oxygen desaturation $(90 \%-92 \%)$ : surgery was scheduled 1 week after the crash. After median sternotomy, the pericardium was entered and luxation of the heart through a large pericardial defect $(20 \times 10 \mathrm{~cm})$ on the left side was seen. The free edge of the pericardium was smooth and no adhesions were present (Figure 2). After TV inspection, the anterior leaflet was found to be flail owing to papillary muscle tear with the heads split in two (Figure $3, A)$. After connection of the two papillary heads (Figure 3, B), the anterior papillary muscle was reinserted onto its cardiac end with 5-0 polypropylene buttressed with Teflon felt. The TV was bicuspidized by closing the anteroseptal commissure; a cleft on the anterior leaflet was also repaired. Finally, tricuspid annuloplasty was performed with autologous pericardium tailored on a $\varnothing$ 30-mm Carpentier-Edwards sizer (Edwards Lifesciences, Irvine, Calif). Intraoperative TEE showed no residual regurgitation (Figure 1, B). Postoperative recovery was uneventful with patient discharge on the fifth postoperative day. At 1-year follow-up, the patient is in good condition (New York Heart Association functional class I) with no echocardiographic evidence of TV regurgitation.

\section{DISCUSSION}

With increasing numbers of motor vehicle crashes, attention to blunt chest trauma is rising among hospitals.
Although rare, TTR is the most commonly reported traumatic valve injury with about 150 cases described to date. ${ }^{4}$ Defects of the pericardium are also rare entities, which have traditionally been divided into two groups: congenital defects and pericardial tears, resulting from blunt trauma. Congenital defects are very uncommon with no more than 200 cases described in the literature. ${ }^{3}$ Most pericardial defects are asymptomatic, although rarely they have been associated with chest pain, dyspnea, and dysrhythmias. Association of TTR and pericardial defect, as seen in the case herein, is very uncommon with only 13 cases described to date. ${ }^{2,4,5}$ However, in more than half of the cases the defects are described as pericardial tear, suggesting traumatic etiology (spurious association). Considering our patient's history, chest film, and TEE findings, it was clear that TV rupture was traumatic. On the contrary, the pericardial defect found at surgery was

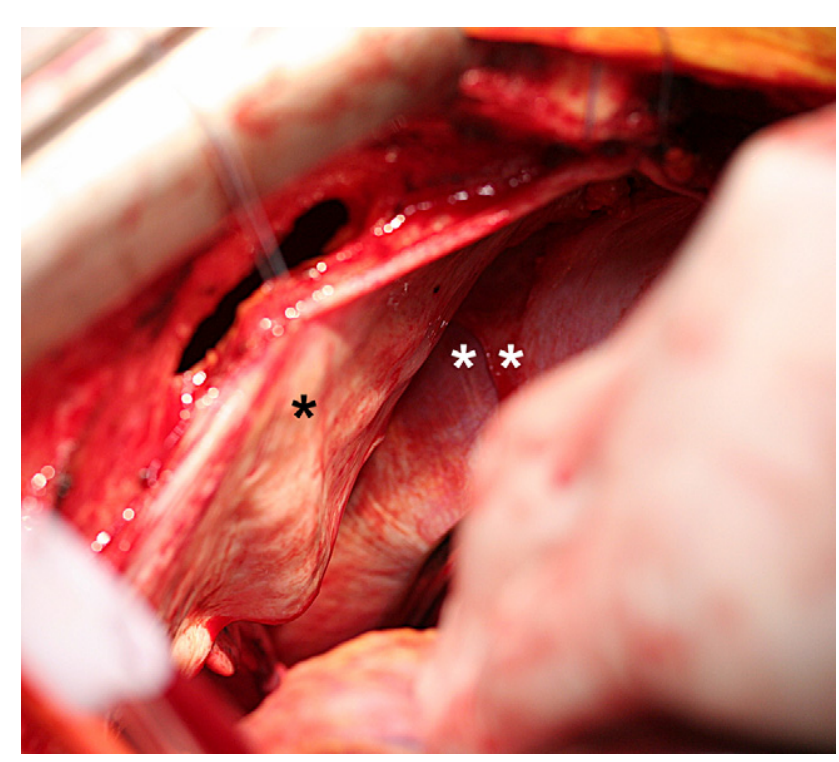

FIGURE 2. Large pericardial defect seen after pericardiotomy: the free edge of the defect is smooth. Black asterisk, Pericardium; white asterisks, left hemidiaphragm. 

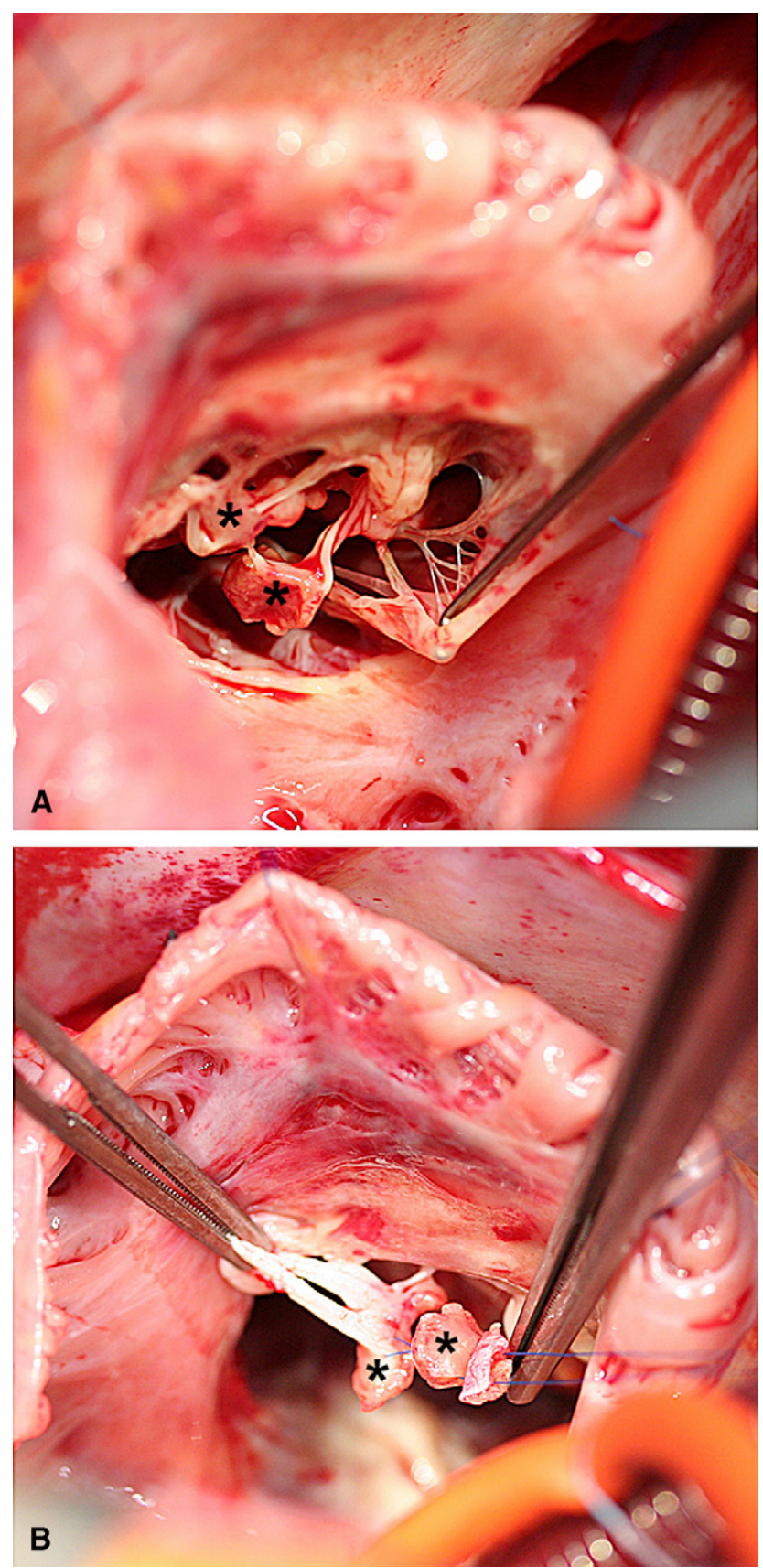

FIGURE 3. A, Anterior TV papillary muscle head torn and split in two, explaining leaflet flail. B, Reconnection of the papillary heads during TV repair. Black asterisks, Papillary heads. likely unrelated to the accident. Currently, no specific criteria for diagnosis of pericardial defects exist, considering that most of them are detected incidentally during operations for other disorders. Furthermore, differential diagnosis between congenital pericardial defects and posttraumatic pericardial tears can only be made at the time of operation and is still a matter of debate. Usually, congenital pericardial defects are large, with smooth edges, like the one in the patient herein, whereas pericardial ruptures have irregular margins with pleuropericardial adhesions. ${ }^{4}$ It has been reported that congenital pericardial defects may promote chronic TV insufficiency by a progressive elongation of the chordae during a period of years. ${ }^{5}$ The case here described suggests that congenital pericardial defects may also expose to acute TV regurgitation. Although TV regurgitation could be caused by the accident per se, the relationship between the two was likely not serendipitous, considering that when the chest was opened the heart was found to be herniated in the left pleural cavity. We speculate that interruption of the pericardial sac may alter the elastic mechanical properties, which protect the heart against sudden rise in intrathoracic pressure (deceleration injury). This condition may predispose to acute compression and torsion of the right heart, causing in turn chordal and papillary rupture, ${ }^{4}$ as previously described in the chronic setting. ${ }^{5}$ On the basis of these considerations, concomitant repair of any associated pericardial defect seems advisable. Furthermore, incidental finding of defects of the left pericardium with cardiac luxation may warrant consideration for prophylactic surgical treatment.

\section{References}

1. Moainie SL, Guy TS, Plappert T, Gorman JH III, Gorman RC. Correction of traumatic tricuspid regurgitation using the double orifice technique. Ann Thorac Surg. 2002;73:963-5.

2. Prenger KB, Ophuis TO, Van Dantzig JM. Traumatic tricuspid valve rupture with luxation of the heart. Ann Thorac Surg. 1995;59:1524-7.

3. Drury NE, De Silva RJ, Hall RMO, Large SR. Congenital defects of the pericardium. Ann Thorac Surg. 2007;83:1552-3.

4. Higashikawa M, Nishio M, Kanamori T, Nakamura Y, Kinoshita M. Traumatic tricuspid regurgitation associated with congenital partial pericardial defect. Jpn Circ J. 1997;61:358-60.

5. Rashid A, Ahluwalia G, Griselli M, Scheuermann-Freestone M, Neubauer S, Gaztoulis M. Congenital partial absence of the left pericardium associated with tricuspid regurgitation. Ann Thorac Surg. 2008;85:645-7. 